Seção: Inovações Educacionais

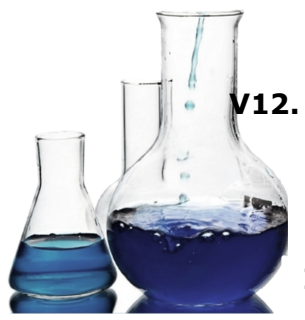

Enviado em: $13 / 04 / 2013$

\title{
Perfil - Biomoléculas
}

\section{Perfil - Biomolecules}

Paula Perazzo de Souza Barbosa ${ }^{1 *}$, Tatiane Santi Gadelha², Carlos Alberto de Almeida Gadelha², Darlene Camati Persuhn,2

*e-mail: paulabio05@hotmail.com

${ }^{1}$ Programa mestrado em Biologia Celular e Molecular da Universidade Federal da Paraíba - UFPB.

${ }^{2}$ Departamento de Biologia Molecular, Universidade Federal da Paraíba - UFPB.

Agência de fomento: CAPES

\begin{abstract}
Resumo
A Bioquímica é uma ciência complexa e importante que estuda os aspectos químicos dos organismos vivos, partindo da estrutura das biomoléculas até o seu metabolismo. Existem dificuldades no processo de aprendizagem de bioquímica devido à necessidade de relacionar conceitos químicos e sua relevância no contexto das moléculas biológicas. Considerando estes aspectos, o presente trabalho tem como objetivo apresentar um jogo didático, Perfil - biomoléculas, que possa ser utilizado nas aulas de todos os cursos onde bioquímica faça parte da grade curricular. É necessário diversificar as estratégias didáticas na educação superior objetivando obter melhores resultados no processo de aprendizagem.
\end{abstract}

Palavras-chave: aprendizagem, bioquímica, jogo.

\begin{abstract}
Biochemistry is an important and complex science which studies the chemical aspects in living organisms, starting in the structure of molecules, reaching to their metabolic relationships. Learning biochemistry is difficult due to the need to connect the chemical concepts and their relevance in the context of biological molecules. Considering these aspects, this work aims to present a didactic game, Profile - biomolecules, which can be used in Biochemistry courses. It is necessary to diversify the teaching strategies in College education in order to obtain better results in the learning process.
\end{abstract}

Keywords: learning, Biochemistry, game. 


\section{Ficha da atividade desenvolvida}

Título: PERFIL - biomoléculas.

Público alvo: Estudantes de cursos das diferentes áreas do conhecimento que precisam dominar os conceitos estruturais e funcionais das biomoléculas.

Disciplinas relacionadas: Bioquímica Estrutural, Biologia Celular, Genética Básica.

Objetivos educacionais: Inter-relacionar as biomoléculas, suas características estruturais, classificação e função.

Justificativa de uso: Trata-se de uma estratégia de ensino versátil que pode ser totalmente desenvolvida em sala de aula, com a colaboração dos estudantes, ou então ser apresentada de forma elaborada pelo professor. Emprega materiais simples e baratos podendo ser desenvolvido com turmas de qualquer tamanho, desde que os alunos trabalhem em grupos. Apresenta caráter lúdico, proporcionando um espaço agradável de aprendizado.

Conteúdos trabalhados: Estrutura, características, classificação e funções de aminoácidos, peptídeos, proteínas, enzimas, lipídios, ácidos nucléicos. 


\section{Introdução}

A Bioquímica é uma ciência complexa e importante que estuda os processos químicos envolvidos nos organismos vivos. Esses processos abrangem as biomoléculas, tratando das suas estruturas, funções e processos metabólicos [1], caracterizando assim uma ciência essencialmente dinâmica.

Neste sentido, seria necessário o estabelecimento de estratégias de ensino voltadas a estimular a atenção dos discentes e seu envolvimento com os temas [2], e que permitam o trabalho paralelo dos conceitos químicos elementares importantes para o entendimento dos diferentes grupos de moléculas biológicas, pois na educação universitária também se faz necessária a implementação de propostas inovadoras para impulsionar o desenvolvimento dos educandos [3].

Uma alternativa viável e interessante a ser pensada seria a realização de atividades lúdicas em paralelo com as aulas teórico-práticas de bioquímica, pois elas normalmente motivam e atraem o raciocínio e a reflexão, o que estimula a construção do conhecimento mediado pelo professor.

Uma ferramenta que pode ser utilizada para dinamizar as aulas é o jogo, que possibilita um espaço de discussão onde o lúdico passa a ter papel importante na relação ensino-aprendizagem [4, 5], seja no ensino básico ou superior, representando assim, uma maneira mais prazerosa de trabalhar as dificuldades do processo [6]. Jogos que tradicionalmente são competitivos podem se tornar cooperativos permitindo que os alunos descubram novos aspectos, deixando margem até mesmo para que eles os remodele ou até mesmo criem novos jogos [7].

Nesse caso, o jogo não seria o fim, mas o eixo que conduz a um conteúdo didático específico, resultando no empréstimo de uma ação mais divertida para a aquisição de informações [8] e até mesmo rompendo relações competitivas que possam existir entre os alunos [7]. Apesar da utilização de jogos didáticos não ser novidade [9], ainda hoje eles são pouco utilizados nas instituições de ensino, e seus benefícios são desconhecidos por muitos professores [10].

O uso do jogo didático tem sido proposto no contexto do ensino de bioquímica. Nessa disciplina, o tema mais enfatizado em jogos didáticos é o metabolismo. O primeiro relato científico desta categoria é "The game of metabolismo" [11] que consiste de um 
jogo de tabuleiro no qual o "ATP é gerado" pelos alunos através do trânsito por diferentes vias metabólicas. No jogo "Race to Glucose", o tabuleiro contém figuras com os intermediários das vias metabólicas e o objetivo é atingir a glicose partindo do glutamato, estando envolvidas a gliconeogênese, a glicólise e o ciclo dos ácidos tricarboxílicos [12]. Já a versão bioquímica do jogo War, denominado War Metabólico, tem como objetivo o domínio dos intermediários das vias metabólicas que estão no tabuleiro [13].

Considerando as dificuldades enfrentadas pelos alunos de nível superior com relação à compreensão das biomoléculas, o presente trabalho teve como objetivo a produção do jogo "Perfil - biomoléculas", uma versão bioquímica do homônimo produzido por uma empresa de brinquedos brasileira, como opção didática nas aulas dessa disciplina.

\section{Procedimentos e Recursos}

Os materiais necessários ao desenvolvimento desta atividade são basicamente: livros didáticos para consulta, fichas feitas de papel grosso do tipo cartão, canetas hidrocor, cartolina guache para a montagem do tabuleiro, papel A4 colorido e peões para jogo de tabuleiro.

\subsection{Desenvolvimento das fichas para elaboração do jogo}

Termos bioquímicos deverão ser distribuídos a grupos de alunos para que os mesmos possam confeccionar as fichas. A figura 1 apresenta um modelo para as fichas do jogo.

Fica a critério do professor quais palavras selecionar, sendo interessante que sejam aquelas relacionadas a conteúdos cujos alunos tiveram mais dificuldade de assimilar durante as aulas expositivas.

Também é importante que cada equipe receba termos de todas as classes de moléculas a fim de diversificar os temas de estudo durante a etapa de elaboração. Os termos podem variar de constituintes simples como, por exemplo, arginina, D-glicose e ácido palmítico; a moléculas mais complexas como glicogênio, esfingomielina e RNA mensageiro. Outros termos mais relacionados à função, classificação ou fundamentação teórica das moléculas poderão ser utilizados: ponto isoelétrico, estrutura terciária de 
proteínas, constante de Michaelis Menten, entre outros.

De posse do termo, os alunos serão orientados a descrevê-lo em no mínimo quatro e no máximo seis pistas diretas, iniciando com as mais gerais e atingindo as que levam às respostas de forma mais óbvia. Por exemplo: 1 - pertence ao grupo dos carboidratos; 2 é um monossacarídeo; 3 - é uma aldoexose; 4 - é o monossacarídeo mais abundante na natureza; 5 - elemento estrutural do amido e do glicogênio; resposta: D-glicose.

O diferencial do jogo reside justamente no exercício prévio de descrever as moléculas. O aluno recebe o termo e deverá pesquisá-lo, identificar a qual classe bioquímica pertence (esta deverá ser a primeira pista) ou a qual delas se refere (como no caso do ponto isoelétrico, que faz referência a aminoácidos ou a proteínas). Em seguida, precisará identificar características que progressivamente descrevam o termo, sem evidenciá-lo com facilidade. Este processo é diferente de uma simples conceituação, pois para deixar claro na carta qual termo está descrevendo, pistas serão apresentadas que, sequencialmente, levam a uma resposta única.

\subsection{0 jogo}

A proposta consiste em montar um jogo de tabuleiro cujo objetivo é chegar ao final de 115 casas, acertando com o mínimo de pistas possível os termos bioquímicos descritos. A fim de tornar o jogo mais ágil, paralelamente, o tabuleiro tem os passos diferenciados por cores que farão referência a um grupo de moléculas: amarelo - lipídios; azul - ácidos nucleicos; verde - aminoácidos, peptídeos, proteínas e enzimas; vermelho carboidratos. Quando a resposta de uma determinada carta corresponder a uma molécula do grupo da cor em que peão ficar posicionado, o mesmo poderá mover-se o dobro de espaços. Caso o aluno não reconheça ou se esqueça de solicitar, será punido retornando à posição anterior. Na figura 2 é sugerido um modelo para o tabuleiro do jogo, 


\section{D-GLICOSE}

$1^{\circ}$ pertence ao grupo dos carboidratos;

$2^{\circ}$ é um monossacarídeo;

$3^{\circ}$ é uma aldoexose;

$4^{\circ}$ é o monossacarídeo mais abundante na natureza;

$5^{\circ}$ elemento estrutural do amido e do glicogênio.

Figura 1. Modelo proposto para as fichas com as pistas das biomoléculas.

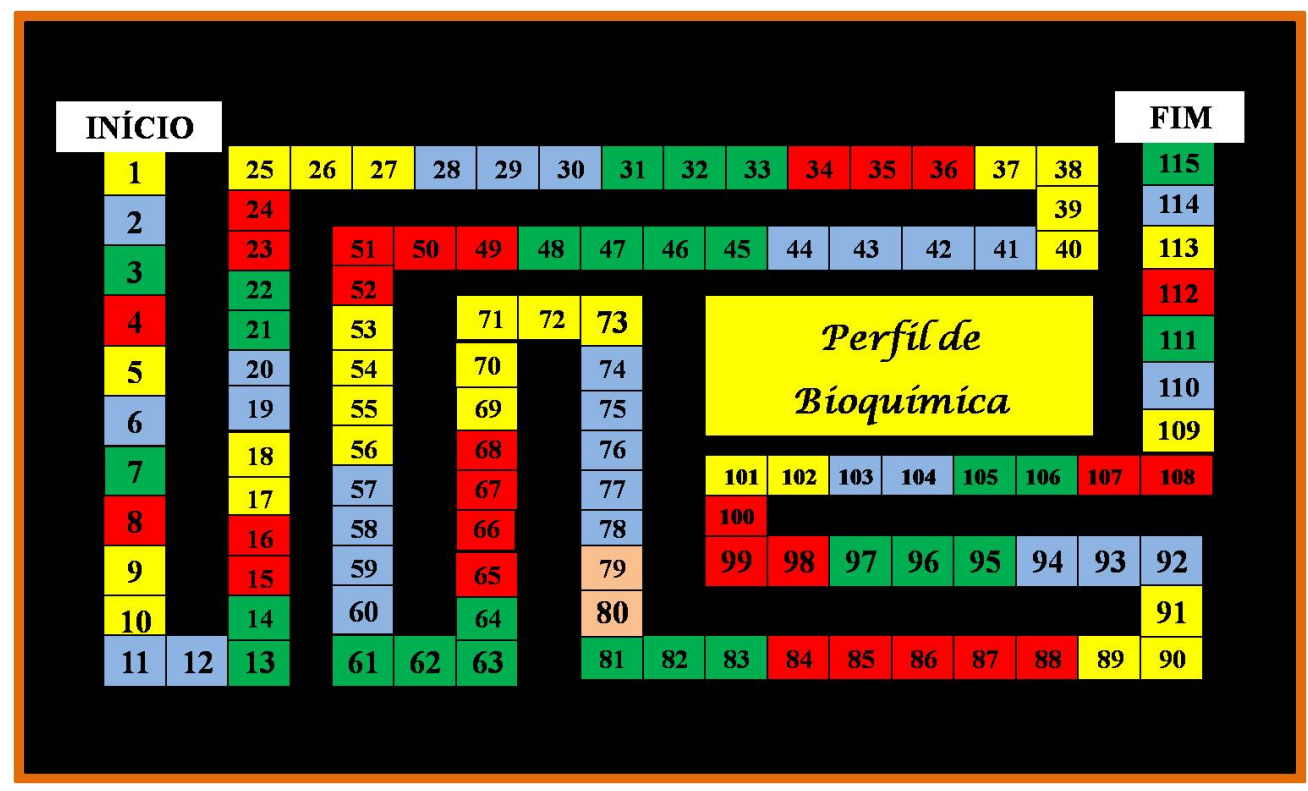

Figura 2. Modelo proposto para o tabuleiro do "Perfil - biomoléculas". Alguns dos espaços deverão apresentar instruções que redirecionem os jogadores para outros locais como, por exemplo: volte três casas, adiante cinco casas ou vá para a casa de número vinte. Os passos também são diferenciados por cores que farão referência a um grupo de moléculas.

\section{Desenvolvimento da Atividade}

Todas as fichas elaboradas pelas equipes serão embaralhadas em uma única pilha. Para jogar, todos os alunos colocam os peões no início do tabuleiro. A relação entre a quantidade de pistas acertadas e o número de espaços percorridos no tabuleiro, bem como as demais regras do jogo são combinadas com a turma.

Para iniciar o jogo, define-se a primeira equipe a desafiar. Um desafiante lerá uma a uma as pistas do primeiro cartão do monte. Quanto menos pistas utilizadas para descobrir o termo em questão, maior é o espaço a percorrer no tabuleiro. Por exemplo, caso alguém acerte o primeiro termo já na primeira pista, percorre dez casas; se o acerto 
for depois da leitura da segunda pista, percorre oito casas e assim por diante. Se o participante errar após a leitura da última pista, permanecerá na mesma casa do tabuleiro. Desta forma, são favorecidos aqueles que conseguem descobrir com o menor número de pistas qual molécula está sendo descrita.

Ao acertar uma resposta e andar o número de casas correspondente às pistas necessárias para o acerto, o aluno deverá verificar a cor da casa sobre a qual ficará posicionado o peão. Caso a resposta dada tenha relação direta com o grupo de moléculas da cor, o peão deverá andar o dobro de espaços. Caso o aluno não reconheça a relação e esta exista, deverá retornar à posição inicial. Vence o jogo quem atingir o final do tabuleiro primeiro.

\section{Resultados}

Durante a produção e aplicação do jogo "Perfil - biomoléculas" em uma turma de $1^{\circ}$ período do curso de Farmácia da UFPB, na disciplina Bioquímica Estrutural, os estudantes foram motivados a uma participação mais ativa e dinâmica com a disciplina. Como o jogo foi realizado com grupos de alunos, ele também favoreceu uma construção coletiva do conhecimento.

O envolvimento na produção das fichas com as pistas sobre as biomoléculas e na elaboração das regras do jogo foram pontos positivos observados. Os acadêmicos estiveram envolvidos, concentrados e principalmente motivados no processo, o que os levou a raciocinar durante o jogo e os auxiliou a articular os conceitos químicos e biológicos. O professor atuou no papel de mediador e não de transmissor de conceitos

Na disciplina em que o jogo foi aplicado, a ementa conta apenas com o estudo das biomoléculas. É comum, ao final do semestre, os alunos apresentarem dificuldades, confundindo termos, conceitos e características. O preparo das fichas e, posteriormente, o exercício de jogar, proporcionou um espaço de revisão de todos os assuntos, que foram antecipadamente estudados para a produção das fichas. Alguns termos eram mais complexos e suas definições e classificações não estavam completas no livro adotado, levando os estudantes a explorar outras bibliografias, ampliando a leitura e a visão sobre o respectivo tema. 


\section{Impacto no Processo Ensino-Aprendizagem}

Aulas expositivas certamente são importantes, mas o seu uso exclusivo pode reduzir o interesse dos alunos e tornar a disciplina pouco interessante mesmo que os estudantes estejam dispostos [14, 15], pois elas tendem a se concentrar fortemente em fatos, definições e eventos isolados [16].

Outro detalhe relevante é que cada aluno é diferente e, portanto terá um estilo de aprendizagem diferente [17]. Na sala de aula tradicional os estudantes podem sentir o material muito difícil ou muito fácil, não podendo experimentar diferentes estilos de aprendizagem ou utilizar outro método de resolução do problema, sem o risco de falhar ou receber uma nota ruim $[18,19]$.

Os professores devem trabalhar mais com recursos alternativos aos arquivos projetados e livros, uma vez que despertam maior interesse dos discentes, bem como buscar que os próprios educandos apresentem seus interesses ou mesmo criem junto com o professor o recurso desejado [20]. Para os alunos do nível superior, o jogo pode ser considerado uma novidade durante as aulas, pois normalmente atividades lúdicas são desenvolvidas apenas no ensino básico.

Assim, os jogos educacionais podem ser excelentes instrumentos já que têm o potencial de gerar o estímulo no discente [21]. Se usados adequadamente, tornam a aprendizagem menos mecânica [22] ao mesmo tempo em que possibilita de forma alegre e ativa a construção do conhecimento permitindo o acompanhamento desse processo pelo professor [23], pois mesmo que o estudante considere o jogo difícil, ele sabe que é factível e que seu esforço valerá a pena.

\section{Conclusões}

Através das observações realizadas durante o processo de produção e aplicação do jogo, pode-se inferir que a metodologia empregada para o desenvolvimento do mesmo se mostrou adequada para abordar a análise estrutura e funcional dos diferentes grupos de biomoléculas. A proposta metodológica apresentada na forma do jogo "Perfil biomoléculas" apresenta baixo custo de produção e pode ser elaborado pelos alunos em qualquer curso de Bioquímica. Pode ser utilizada como material de apoio para a revisão e 
comparação dos grupos moleculares estudados, a fim de auxiliar na aquisição, revisão e fixação de conceitos.

\section{Referências}

[1] Albuquerque MAC, Amorim AHC, Rocha JRCF, Silveira LMFG, Neri DFM. Bioquímica como Sinônimo de Ensino, Pesquisa e Extensão: um Relato de Experiência. Rev bras educ méd. 2012; 36 (1): 137-142.

[2] Azevedo ANP, Amoretti MSM, Timm MI, Zaro MA. Mapas Conceituais e o Jogo: Estratégias Pedagógicas de Ensino e Aprendizagem de Bioquímica. Inform Educ. 2004 Jan./Jun.; 7 (1): 59 - 71.

[3] Magnareli G, Quintana MM, García L, De Rosso EV, Cabrera L, Ruíz-Moreno L. El trabajo en pequeños grupos facilita La enseñanza-aprendizaje de Bioquímica. Rev bras educ méd. 2009; 33 (3): $374-392$.

[4] Legey AP, Mol ACA, Barbosa JV, Coutinho CMLM. Desenvolvimento de Jogos Educativos Como Ferramenta Didática: um olhar voltado à formação de futuros docentes de ciências. Rev Educ Ciênc Tecnol. 2012; 5 (3): 49- 82.

[5] Morales E. El uso de los videojuegos como recurso de aprendizaje en educación primaria y Teoría de la Comunicación. Diálogos de la comunicación. 2009 Jul; 78: 1-12.

[6] Antunes AM, Sabóia-Morais SMT. O jogo educação e saúde: uma proposta de mediação pedagógica no ensino de ciências. Experiência em Ensino de Ciências. 2010; 5 (2): 55-70.

[7] Soriano PC, Beristain CM. La alternativa del juego I: juegos y dinámicas de educación para la paz. Madrid: Los libros de la catarata; 1995. p. 254.

[8] Kishimoto TM. Jogo, brinquedo, brincadeira e a educação. São Paulo: Cortez; 1996. p.183.

[9] Santos AB, Guimarães CRP. A utilização de jogos como recurso didático no ensino de zoologia. Rev. electrón. investig. educ. cienc. [periódicos da Internet]. 2010 [acesso em 21 de outubro de 2012]; 5 (2); Disponível em http://www.scielo.org.ar/scielo.php? script=sci_arttext\&pid=S185066662010000200006\&lang=pt

[10] Campos LML, Felício AKC, Bortoloto TM. A produção de jogos didáticos para o ensino de ciências e biologia: uma proposta para favorecer a aprendizagem. Cad. núcl. ens. [periódicos da Internet]. 2003 [acesso em 12 de dezembro de 2012]. Disponível em http://www.unesp.br/prograd/PDFNE2002/aproducaodejogos.pdf

[11] Goodman R. The game of "metabolism." Am Biol Teach.1972; 34 (2):75-78.

[12] Rose TM. A Board Game to Assist Pharmacy Students in Learning Metabolic Pathways. Am J Pharm Educ. 2011 Nov.; 75 (9): 183. doi: 10.5688/ajpe759183.

[13] Anjos C, Gandra M. Metabolic war: a variation for metabolic biochemistry learning of a worldly known board game. Revista de Ensino de Bioquímica. [periódicos da Internet]. 
2008 [acesso em 16 de outubro de 2013]. Disponível em: http://bioquimica.org.br/revista/ojs/index. php/REB/article/view/68/61

[14] Wood EJ. Biochemistry is a Difficult Subject for Both Student and Teacher. Biochem Educ. 1990 Oct.; 18 (4): 170 - 172.

[15] Norman GR, Schimidt HG. The Psychological Basis of Problem-Based Learning: A Review of the Evidence. Acad. Med. 1992 Sept; 67(9): 557 - 567.

[16] Gee JP. What video games have to teach us about learning and literacy, revised and updated. Basingstoke: Palgrave Macmillan; 2008.

[17] Rapini S. How Games Facilitate Learning. [periódicos da Internet]. 2012. [Acesso em 01 de outubro de 2013]. Disponível em: http://gamingforeducation.weebly.com/howgames-facilitate-learning.html

[18] Squire K. Video Games and Learning: Teaching and Participating Culture in the Digital Age. New York: Teachers College Press; 2011. p. 253

[19] Mcgonigal J. Reality Is Broken: Why Games Make Us Better and How They Can Change the World. Penguin Press; 2011. p. 416.

[20] Santos AB, Guimarães CRP. A utilização de jogos como recurso didático no ensino de zoologia. Rev. electrón. investig. educ. cienc. [periódicos da internet]. 2010 [acesso em 12 de dezembro de 2012]; 5 (2); Disponível em http://www.scielo.org.ar/scielo.php? script=sci_arttext\&pid=S185066662010000200006\&lang=pt

[21] Araújo NMS, Ribeiro FR, Santos SF. Jogos pedagógicos e responsividade: ludicidade, compreensão leitora e aprendizagem. Bakhtiniana 2012 Jan./Jun.; 7 (1): 4-23.

[22] Mattos RCF, Faria MA. Jogo e Aprendizagem. Rev. eletr. sab. educ. [periódicos da Internet]. 2011 [acesso em 21 de outubro de 2012]; 2 (1); Disponível em http://www.facsaoroque.br/novo/publicacoes/pdf/v2-n1-2011/Regiane.pdf

[23] Canal PPC, Queiroz, SS. Procedimentos de contagem de pontos em um jogo com conteúdo matemático. Psicol. Esc. Educ. 2012 Jan./Jun.; 16 (1): 25-33.

\section{Agradecimentos}

Aos alunos do $1^{\circ}$ período do curso de Farmácia da UFPB, turma 2012.1, que

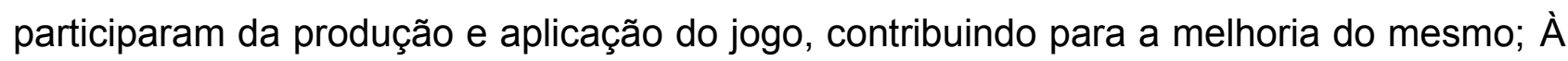
professora Darlene Camati Persuhn, por ter aceitado a orientação e a aplicação do jogo em sua sala de aula; e aos professores Tatiane Santi Gadelha e Carlos Alberto de Almeida Gadelha, pelas sugestões para o desenvolvimento dessa atividade.

O presente trabalho foi realizado com apoio do Programa de Reestruturação e Expansão das Universidades Federais - REUNI e da CAPES - Coordenação de Aperfeiçoamento de Pessoal de Nível Superior - Brasil. 